\title{
Impact of Dislocation Density and Mobility on Yielding Behavior in Quenched Medium-carbon Martensitic Steel Tempered at Low Temperature
}

\author{
Hiroyuki UCHIMA, ${ }^{1)}$ Masayoshi KUMAGAI, ${ }^{2 *}$ Junzo SHIMBE, ${ }^{1)}$ Akihiro TANABE, ${ }^{1)}$ Yuta MIZUNO ${ }^{1)}$ and \\ Yusuke ONUKI ${ }^{3)}$ \\ 1) THK Co., Ltd 2-12-10 Shibaura, Minato-ku, Tokyo, 108-8506 Japan. \\ 2) Department of Mechanical Systems Engineering, Faculty of Science and Engineering, Tokyo City University, 1-28-1 \\ Tamazutsumi, Setagaya-ku, Tokyo, 158-8557 Japan. \\ 3) Frontier Research Center for Applied Atomic Sciences, Ibaraki University, 162-1 Shirakata, Tokai, Ibaraki, 319-1106 Japan.
}

(Received on September 7, 2021; accepted on October 26, 2021; J-STAGE Advance published date: January 7, 2022)

\begin{abstract}
Middle-carbon martensite steels are vital materials for mechanical components and their mechanical properties have attracted significant interest. However, the decrease in the elastic limit of the as-quenched materials is one of the remaining puzzles. Herein, we quantitatively characterized the dislocation density and its structure in the as-quenched and tempered martensite steel by neutron diffraction line profile analysis and discussed their impact on the yield stress. The dislocation density in the as-quenched specimen was the highest at $9.7 \times 10^{15} \mathrm{~m}^{-2}$, while it decreased with an increase in the tempering temperature. In addition, the component ratios of edge and screw dislocations decreased and increased, respectively, depending on the increase in the tempering temperature. The dislocation arrangement parameter (M) varied between the tempering temperatures of 220 and $290^{\circ} \mathrm{C}$. Although there was a large difference between the yield stress obtained from the tensile test and that estimated from the dislocation density, the experimental results could be explained by correcting them with the inverse of $M$ value as an index showing the effective dislocation density ratio.
\end{abstract}

KEY WORDS: martensite; medium-carbon steel; neutron diffraction; line profile analysis; mobile dislocations; elastic limit; yield stress.

\section{Introduction}

Steel is the most common engineering material for mechanical products. It possesses several advantages, such as high productivity and strength, which can be easily controlled by choosing the type and additive element or thermal treatment. ${ }^{1-3)}$ In particular, the hardness and ultimate tensile strength (tensile strength) of middle to high-carbon steels can be easily improved owing to their hardenability by quenching. Therefore, middle- and high-carbon steels are essential materials for bearings and gears in industry. Because as-quenched materials are brittle and have low toughness, tempering is performed following quenching to suppress brittleness and improve toughness. Muir et al. reported that the changes in the elastic limit, yield strength, and tensile strength are associated with tempering temperature in steels containing carbon $(0.2,0.41$, and $0.82 \mathrm{wt} \%){ }^{1)}$

\footnotetext{
* Corresponding author: E-mail: mkumagai@tcu.ac.jp
}

\begin{abstract}
Subsequently, many studies on martensite with respect to heat treatments and their correspondence to mechanical properties have been conducted. ${ }^{3-7)}$ Quenched martensite generally contains a number of dislocations and exhibits a high tensile strength. While the elastic limit of the asquenched material is surprisingly low, it can be increased by tempering. ${ }^{1,7)}$ A general understanding of the cause of significantly low elastic limit of the as-quenched martensite can lead to the development of more optimal heat treatment conditions for hardened carbon steels.

Galindo et al. demonstrated a comprehensive prediction of the yield stress of lath martensite. ${ }^{8}$ Although its model can predict yield stresses, the decrease in elastic limit on asquenched or low temperatures tempered martensite cannot be assumed. Several reasons for the decrease in the elastic limit of as-quenched materials have been proposed, such as mobile dislocations, ${ }^{9,10)}$ retained austenite, ${ }^{11)}$ and intergranular stress ${ }^{1,12)}$ however, these have not been completely confirmed yet.
\end{abstract}


Studies on microstructures such as dislocation structures are commonly conducted using transmission electron microscopy. However, X-ray and neutron diffractions are considered promising alternatives. The shape of the diffraction line profiles depends on the crystallinity of the specimen metals; thus, line profile broadening is caused by a large number of lattice defects within the metallic crystal grains. ${ }^{13)}$ Therefore, it is possible to extensively study lattice defects such as dislocations, by inversely analyzing the measured diffraction line profiles based on a physical model. ${ }^{10,14-20)}$ In particular, because martensite has a high dislocation density, diffraction line profile analysis (LPA) possesses great advantages. Furthermore, because the gauge volume has a cubic millimeter scale, it is superior in terms of statistical accuracy, and it can be expected to feature a high correlation with the macroscopic mechanical characteristics. Therefore, some studies have attempted to characterize the dislocation density and substructures in lath martensite using neutron diffraction. ${ }^{19,21,22)}$ In addition to well-reported physical quantities, such as dislocation density and crystallite size in the analysis, other indicators of dislocation arrangement and character can be obtained. $^{23-26)}$

Thus, in the LPA for as-quenched and tempered middlecarbon steel, we focused on the dislocation density and on the aforementioned parameters that are expected to suggest dislocation structures. The impact of the microstructural features determined by LPA on the yield stress is discussed.

\section{Experimental}

\subsection{Specimen}

Normalized middle-carbon steel containing $0.56 \% \mathrm{C}$ (AISI 1552 equivalent) was used. Once the as-received materials were heated to $830^{\circ} \mathrm{C}$ and held there for $3 \mathrm{~h}$, they were quenched in cold quenching oil. After quenching, each specimen was heated to an arbitrary temperature $(140,290$, and $490^{\circ} \mathrm{C}$ ) for $1 \mathrm{~h}$ and cooled in air. The optical microscopy images are shown in Fig. 1. ${ }^{7)}$ The surfaces were etched with a nital solution after mirror-like polishing. The stressstrain curves obtained from tensile tests, which have been reported in a previous study, ${ }^{7)}$ are shown in Fig. 2. Herein, only the results ruptured from internal points were adapted. The mechanical properties of the tensile and hardness tests are shown in Table 1. The $0.2 \%$ proof stress was regarded as the yield stress and elastic limit, and is denoted as the yield stress in the present study.

\subsection{Neutron Diffraction Measurements and Analysis}

The diameter and length of the cylindrical specimens were 5.5 and $10 \mathrm{~mm}$, respectively, for neutron experi-
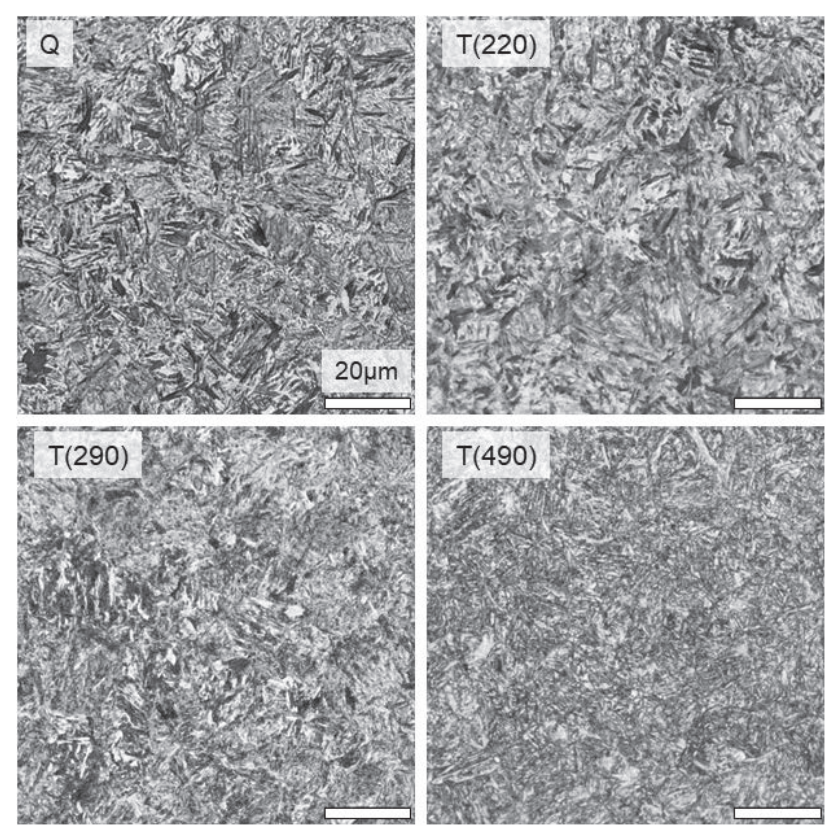

Fig. 1. Optical microscopic images of quenched (Q) and tempered specimens. Tempering is applied at 220,290 , and $490^{\circ} \mathrm{C}$ ( $\mathrm{T}(220), \mathrm{T}(290)$, and $\mathrm{T}(490)$, respectively) and is followed by quenching. ${ }^{7)}$

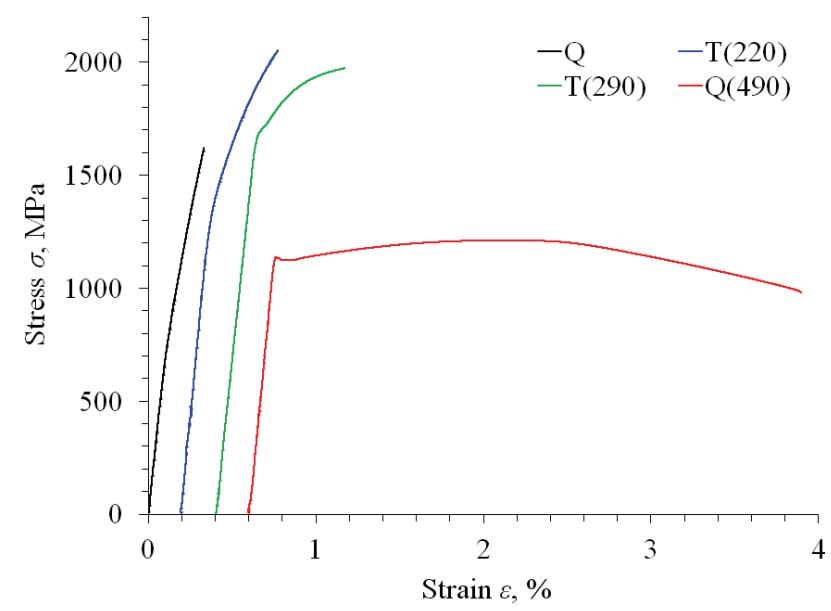

Fig. 2. Stress-strain curves of quenched $(\mathrm{Q})$ and tempered specimens. Tempering is applied at 220,290 , and $490^{\circ} \mathrm{C}$ ( $T(220), T(290)$, and $T(490)$, respectively) and is followed by quenching. ${ }^{\text {) }}$ The strains are respectively shown as offset along the horizontal axis. (Online version in color.)

Table 1. Mechanical properties quenched (Q) and tempered specimens. Tempering is applied at 220,290 , and $490^{\circ} \mathrm{C}$ (T(220), T(290), and T(490), respectively) and is followed by quenching. ${ }^{7)}$

\begin{tabular}{ccccc}
\hline Specimen & Tempered temperature, ${ }^{\circ} \mathrm{C}$ & $\begin{array}{c}\text { Elastic limit } \sigma_{\mathrm{E}}, \mathrm{MPa} \\
\text { (Proof/Yeild stress) }\end{array}$ & Tensile strength $\sigma_{\mathrm{B}}, \mathrm{MPa}$ & $\begin{array}{c}\text { Vickers hardness } H_{\mathrm{V}}, \mathrm{HV} \\
\text { (Rockwell hardness, HRC) }\end{array}$ \\
\hline $\mathrm{Q}$ & 0 (As-quenched) & 1226 & 1641 & $793(63.8)$ \\
$\mathrm{T}(220)$ & 220 & 1468 & 2001 & $644(57.5)$ \\
$\mathrm{T}(290)$ & 290 & 1733 & 1976 & $580(54.1)$ \\
$\mathrm{T}(490)$ & 490 & 1141 & 1223 & $381(39.0)$ \\
\hline
\end{tabular}


ments. The diffraction line profile from a material with a high dislocation density is relatively broader and lower. In addition, the diffraction lines of the retained austenite overlapped with the diffraction lines of martensite. Hence, experiments should be performed using a neutron beam with a millimeter-scale gauge volume and high beam flux. Thus, neutron diffraction measurements were performed at BL20 (iMATERIA) in MLF, J-PARC. ${ }^{27)}$ The accumulation time was 15 min with a $500 \mathrm{~kW}$ of proton accelerator power. Herein, only back-reflection bank detectors were used for the measurement due to higher resolution of the obtained profile shape.

To obtain the dislocation density and related characteristics quantitatively, LPA was performed using the convolutional multiple whole profile (CMWP) fitting software. ${ }^{28,29)}$ In the software, the physical parameters were refined to the computed line profile to be close to the measured line profiles. The physical parameters are as follows: $q=$ dislocation character, $m=$ median crystallite size distribution, $\sigma=$ dispersion of crystallite size distribution, $\rho=$ dislocation density, and $M=$ arrangement parameter of dislocations, where the crystallite size $D$ is given as $D=m$ $\exp \left(2.5 \sigma^{2}\right) .^{30,31)}$

The line profiles between a scattering vector $K \approx 6-13.5$ $\mathrm{nm}^{-1}$ were used for the analysis. The lattice constant is $0.2866 \mathrm{~nm},{ }^{32)}$ and the Burgers vector for $<111>\{110\}$ is $0.2482 \mathrm{~nm}$ in length. The average contrast factor for the $h 00$ reflection is 0.284 , which was obtained via $\mathrm{ANIZIC}^{33)}$ with an elastic stiffness of $c_{11}=228, c_{12}=132$, and $c_{44}=$ $116.5 \mathrm{GPa}^{34)}$ The instrumental broadening factors were determined using the diffraction line profiles of lanthanum hexaboride powder.

\section{Results}

Figure 3 shows the measured diffraction line profiles for each specimen. Diffraction peaks of both martensite and austenite were observed in the as-quenched specimen and in the specimens that were tempered at temperatures less than $290^{\circ} \mathrm{C}$.

Figure 4 shows the parameters obtained via fitting the line profiles: dislocation density $(\rho)$, dislocation character $(q)$, arrangement parameter $(M)$, and crystallite size $(D)$. The dislocation density of the as-quenched specimen was $\rho \sim 1 \times 10^{16} \mathrm{~m}^{-2}$, which decreased with increasing tempering temperature. The dislocation density in the specimen tempered at the highest temperature of $490^{\circ} \mathrm{C}$ was $7 \times 10^{14}$ $\mathrm{m}^{-2}$. The $q$ value, which indicates the fraction of screw and edge dislocations, was 1.82 after quenching, and it increased to 2.26 as the tempering temperature increased; the $q$ values for pure edge and screw dislocations are 1.29 and 2.64, respectively, which were calculated by ANIZIC. ${ }^{33)}$ This means that the ratio of edge dislocations was roughly average in the as-quenched specimen, and the ratio of screws increased by tempering. A similar result has been reported by Shi et $a l .{ }^{21)}$ The edge dislocation can preferentially annihilate due to climbing at elevated temperature. Thus, the ratio of screw dislocation to edge dislocation increased. The $M$ value, which indicates the arrangement of dislocations, was as large as $M \approx 5$ in the as-quenched specimen.

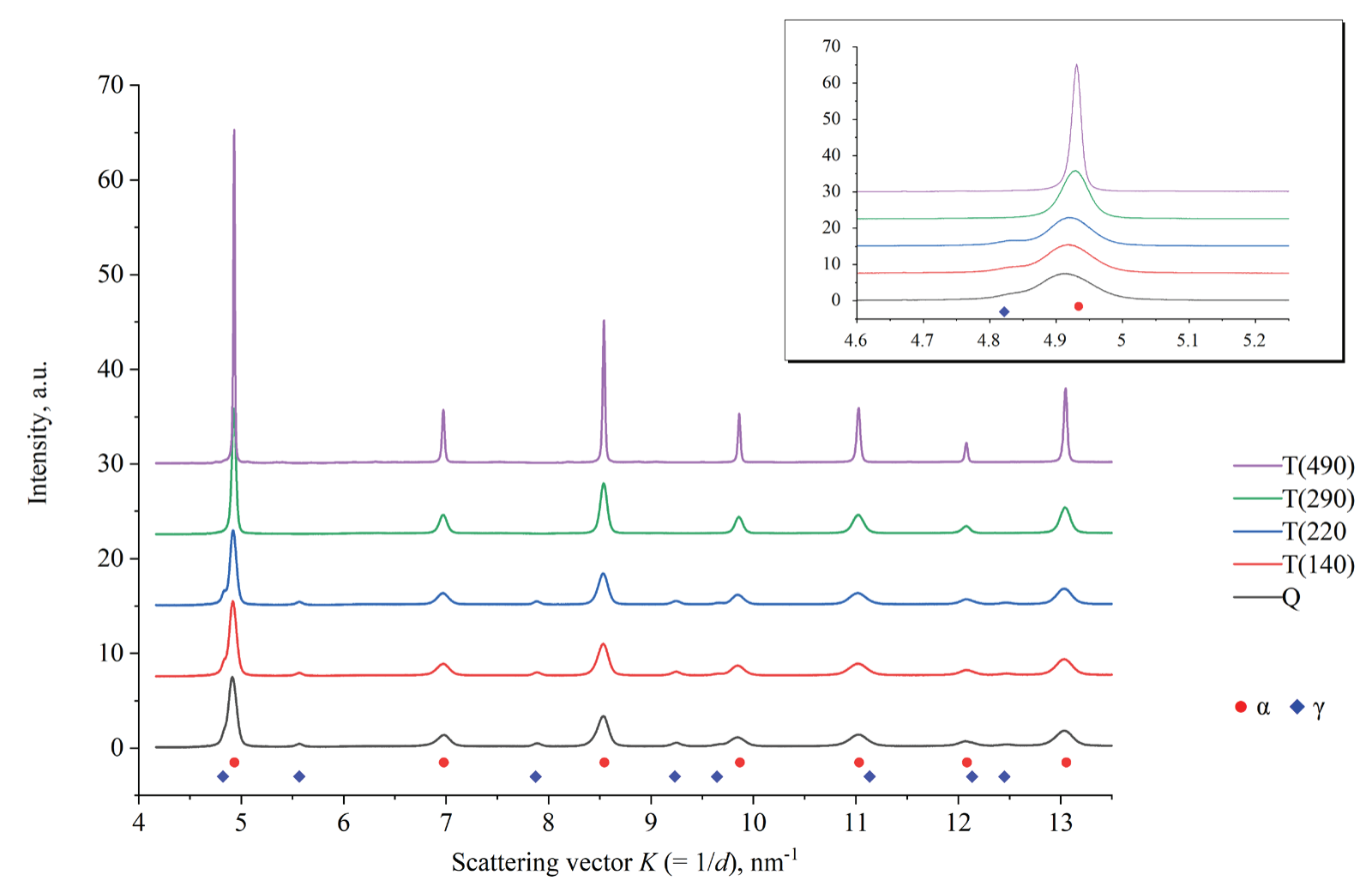

Fig. 3. Neutron diffraction line profiles. The intensity of each profile is arbitrarily offset for visibility. Diffraction peaks of martensite $(\alpha)$ are recognized well in all profiles. Top-right window is zoomed diagram around $K=5$ $\mathrm{nm}^{-1}$. Diffraction of austenite $(\gamma)$ is recognized on the as-quenched specimen, whereas the peak intensities decrease upon tempering. Eventually, the peaks disappear at a tempering temperature of $290^{\circ} \mathrm{C}$. (Online version in color.) 

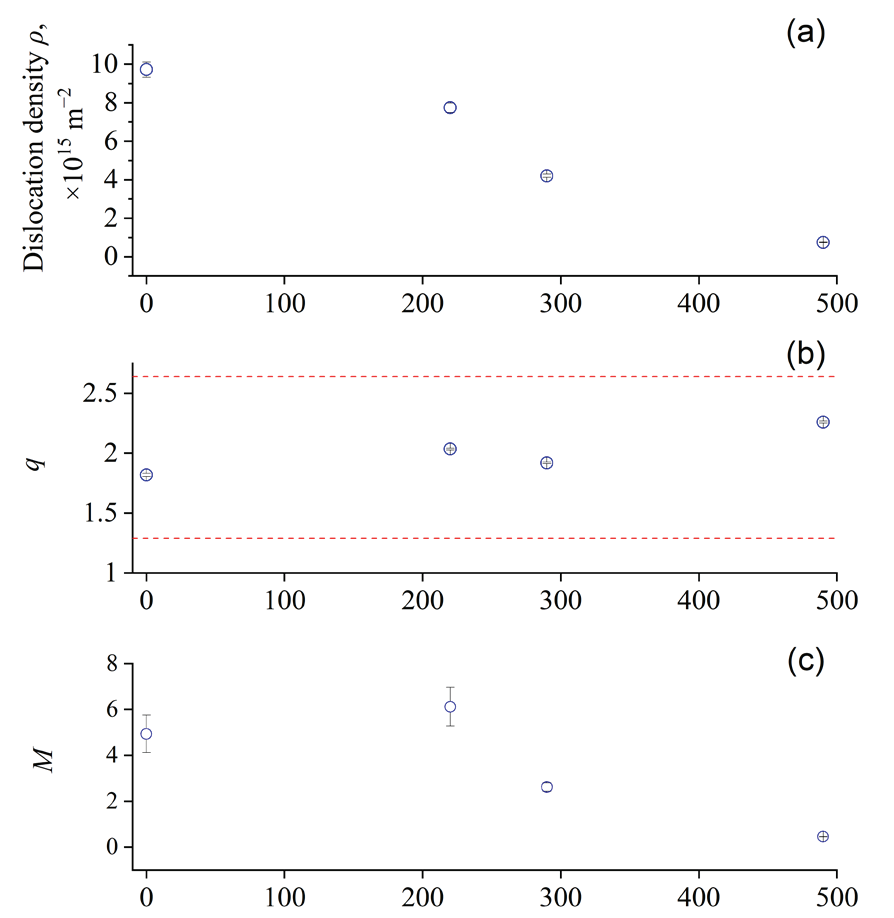

(d)

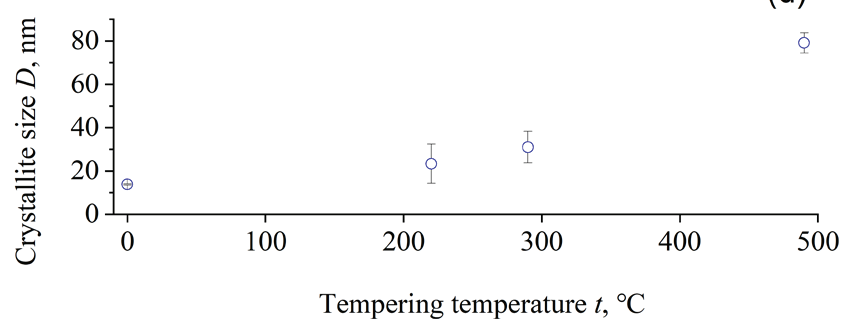

Fig. 4. Obtained parameters as a function of tempering temperature by LPA from top to bottom: dislocation density $(\rho)$, dislocation character $(q)$, arrangement parameter $(M)$, and crystallite size $(D)$. A temperature of $0^{\circ} \mathrm{C}$ indicates the asquenched state without tempering. (Online version in color.)

This means that dislocations were randomly present in the as-quenched specimen. This value was not decreased by tempering at $220^{\circ} \mathrm{C}$, but it steeply decreased by increasing the tempering temperature to $290^{\circ} \mathrm{C}$. It is considered that the dislocations moved significantly within this temperature range $\left(220-290^{\circ} \mathrm{C}\right)$ and interfered with each other.

\section{Discussion}

Although the dislocation density decreased with the increasing tempering temperature (Fig. 4(a)), the yield stress increased below $290^{\circ} \mathrm{C}$ (Fig. 2 and Table 1). Owing to work hardening formulated by the conventional law,, $35-37$ ) the yield stress would decrease. In ultra-low carbon martensitic steels, the relationship between the two parameters, $0.2 \%$ proof stress, and dislocation density is given as $\sigma_{0.2}=100+$ $1.2 \times 10^{-5} \rho^{1 / 2}[\mathrm{MPa}] .^{9)}$ Using this equation, the yield stress is estimated assuming that the slope between the yield stress and the square root of the dislocation density does not change, even if the carbon content changes and only the intercept differs. Here, we determined the intercept $(885$ $\mathrm{MPa})$ of the approximation line as the sum of the residual squares between the approximate line and experimental

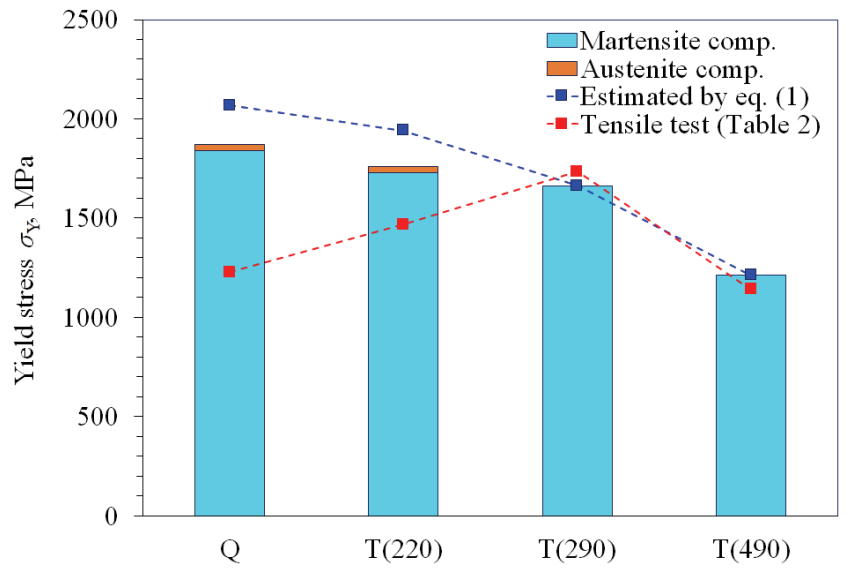

Fig. 5. Estimated yield stress from dislocation density using Eq. (1) and measured yield stress by tensile test (blue and red plots). Bars indicate yield stress partitioning on martensite and retained austenite phases. (Online version in color.)

results of the yield stress to be minimum. Thus, the following equation is obtained:

$$
\sigma_{\mathrm{Y}}^{\rho}=971+1.2 \times 10^{-5} \rho^{1 / 2}
$$

Figure 5 shows the estimated yield stress for each specimen using Eq. (1) and the experimental results (Table 1). The estimated stresses on the as-quenched specimen and the specimen tempered at $220^{\circ} \mathrm{C}$ are significantly larger than the experimental results obtained from tensile tests.

To consider the influence of retained austenite, its phase fractions in each specimen were determined using a software $\left(\mathrm{MAUD}^{38)}\right)$. In the analysis, all the neutron diffraction line profiles obtained from seven bank detectors $(31,39,81$, $90,99,162$, and 149$)^{27)}$ were used. The volume fraction in each specimen was $11 \%$ in the as-quenched specimen and the specimen tempered at $220^{\circ} \mathrm{C}$, and was not recognized in specimens tempered at 290 and $490^{\circ} \mathrm{C}$. The precipitation of retained austenite changed under tempering conditions below $290^{\circ} \mathrm{C}$. Therefore, the effect of the retained austenite was considered as the yield stress. The yield stress can be expressed as the sum of the components of martensite and austenite, when the yield stress of each phase is $\sigma_{\mathrm{Y}}{ }^{\alpha}$ and $\sigma_{Y}^{\gamma}$, where the retained austenite fraction is $R_{\gamma}$. Figure 6 also shows the estimated yield stress components on martensite, $\sigma_{\mathrm{Y}}{ }^{\alpha}\left(1-R_{\gamma}\right)$, and austenite, $\sigma_{\mathrm{Y}}{ }^{\gamma} R_{\gamma}$. The $0.2 \%$ proof stress of a solution-heated SUS316 austenitic stainless steel, $\left.291 \mathrm{MPa},{ }^{16}\right)$ was used as the yield stress of austenite. This value does not represent the exact yield stress of retained austenite in the present specimen, but rather the value of austenite in solution-heated stainless steel, which can be smaller than the true value (the partitioning of austenite is overestimated). The effect of the true yield stress of retained austenite can be estimated to be smaller than this result. The total yield stresses decrease from the value obtained from Eq. (1) owing to the reduction of the martensite phase and approached those obtained from the tensile tests. However, the correction is not sufficient to explain the gap between the experimental and the estimated yield stresses. Although there is an effect of retained austenite, this implies that there are other major factors. Because the volume fraction of cementite is significantly 


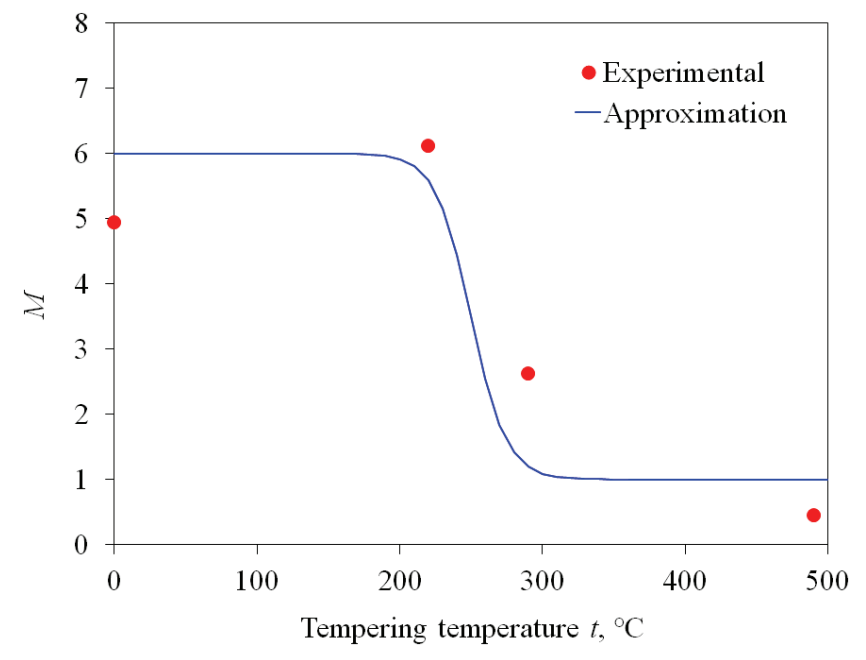

Fig. 6. $M$ value as a function of temperature determined by Eq (2). The $M$ value changes steeply between 220 and $290^{\circ} \mathrm{C}$. (Online version in color.)

smaller than that of the retained austenite, it is not the main factor in the decrease in yield stress.

As aforementioned, the retained austenite is not the main reason for the drop in the yield stresses; however, mobile dislocations might be a reason. Takaki et al. explained that the flow stress is not proportional to the square root of the dislocation density due to the increase in mobile dislocations on ultra-low-carbon martensitic steels. ${ }^{9)}$ The arrangement parameter $M$ is large when dislocations are arranged independently, and becomes small when dislocations interfere with each other and are arranged by forming a dipole. ${ }^{23,28)}$ On the other hand, dislocations that exist independently can move relatively easily, and dislocations become entangled with each other or form dipoles, making it difficult to move. If the dislocations that exist independently and can move relatively easily are assumed to be mobile dislocations, the parameter $M$ is expected to represent quantitative trends in the number of mobile dislocations, which do not have an effect on the yield stress. Thus, we aim to express the dislocation density that contributes to the yield stress, named the effective dislocation density, by eliminating the mobile dislocation component from the total dislocation density using the value of $M$. Because the $M$ value is sensitive to the shape of the line profiles and the analysis results have large scatterings, the $M$ value was approximated using the following equation as a function of tempering temperature $(T)$ :

$$
M(T)=\frac{\beta}{1+e^{\alpha(T-\Delta T)}}+M_{0},
$$

where the parameters $\alpha, \beta, M_{0}$, and $\Delta T$ are constants. Note that the function and its variables were arbitrarily chosen to reproduce the experimental results. Figure 6 shows the lines approximated by Eq. (2) for $M$ values. The constants were determined as $\alpha=0.08^{\circ} \mathrm{C}^{-1}, \beta=5, M_{0}=1$, and $\Delta T=250^{\circ} \mathrm{C}$.

To obtain the effective dislocation density $\rho_{\text {eff }}$, the total dislocation density $(\rho)$ was multiplied by the effective coefficient, the inverse of the obtained $M(T)$ was normalized by $M_{0}$, as follows:

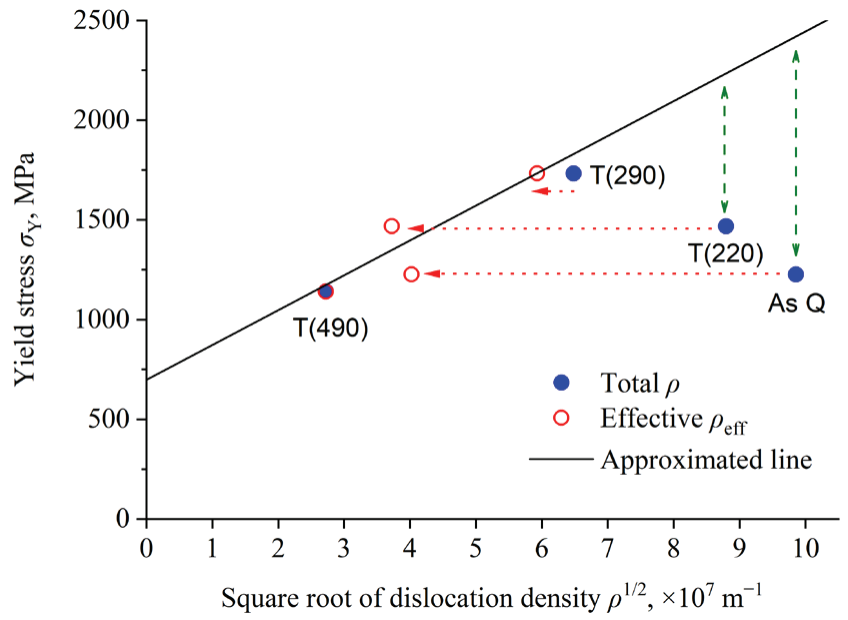

Fig. 7. Yield stress against the square root of dislocation density and its correction as effective dislocation density by the $M$ value. The effective dislocation densities are close to the approximation line based on dislocation hardening. (Online version in color.)

$$
\rho_{\mathrm{eff}}=\rho \frac{1}{M(T) / M_{0}} .
$$

The yield stress was computed using Eq. (1) with the effective dislocation density of each specimen, as shown in Fig. 7. The original plots associated with the total dislocation density moved near the approximate line owing to work hardening; it can be explained that the effective dislocation density, which is estimated from the $M$ values, is the work-hardening component. The approximate line of the relationship between yield stresses and dislocation density is modified as $\sigma_{\mathrm{Y}}^{\text {eff }}=667+1.77 \times 10^{-5} \rho_{\text {eff }}^{1 / 2}$ based on the effective dislocation density.

\section{Conclusion}

The influence of the dislocation density and the structure of the as-quenched and tempered middle-carbon steel on the yielding behavior during tensile tests were studied using LPA with neutrons. The total dislocation density of the as-quenched specimen was the highest, and it decreased with increasing tempering temperature. However, the yield stress does not depend on the total dislocation density. The estimated yield stress from the total dislocation density of specimens tempered at low temperatures $\left(<290^{\circ} \mathrm{C}\right.$ in this study) is significantly higher than that measured by tensile tests. Although retained austenite contributes to the decreasing yield stress, it is not the major factor. In contrast, the experimental results can be well explained by determining the effective dislocation density and yield stress using the dislocation arrangement parameter as the component ratio of mobile dislocations.

\section{Acknowledgement}

The neutron experiment at the Materials and Life Science Experimental Facility of the J-PARC was performed under a user program (Proposal No. 2019AM0026). 


\section{REFERENCES}

1) H. Muir, B. L. Averbach and M. Cohen: Trans. Am. Soc. Met., 47 (1955), 380.

2) H. Bhadeshia and R. Honeycombe: Steels: Microstructure and Properties, 3rd ed., Butterworth-Heinemann, Oxford, UK, (2006), 1.

3) G. Krauss: Steel Res. Int., 88 (2017), 1700038. https://doi.org/10.1002/ srin. 201700038

4) G. R. Speich and W. C. Leslie: Metall. Trans., 3 (1972), 1043. https:// doi.org/10.1007/BF02642436

$5)$ R. A. Grange, C. R. Hribal and L. F. Porter: Metall. Trans. A, 8 (1977), 1775. http://link.springer.com/article/10.1007/BF02646882

6) D. C. Saha, E. Biro, A. P. Gerlich and Y. Zhou: Mater. Sci. Eng. A, 673 (2016), 467. https://doi.org/10.1016/j.msea.2016.07.092

7) J. Shimbe, M. Kumagai, A. Tanabe and Y. Mizuno: Trans. Jpn. Soc. Mech. Eng., 87 (2021), 21-00082. https://doi.org/10.1299/ transjsme.21-00082

8) E. I. Galindo-Nava and P. E. J. Rivera-Díaz-del-Castillo: Acta Mater., 98 (2015), 81. https://doi.org/10.1016/j.actamat.2015.07.018

9) S. Takaki, K.-L. Ngo-Huynh, N. Nakada and T. Tsuchiyama: ISIJ Int., 52 (2012), 710. https://doi.org/10.2355/isijinternational.52.710

10) D. Akama, T. Tsuchiyama and S. Takaki: ISIJ Int., 56 (2016), 1675 https://doi.org/10.2355/isijinternational.ISIJINT-2016-140

11) M. A. Zaccone and G. Krauss: Metall. Trans. A, 20 (1989), 188. https://doi.org/10.1007/BF02647507

12) B. Hutchinson, D. Lindell and M. Barnett: ISIJ Int., 55 (2015), 1114 https://doi.org/10.2355/isijinternational.55.1114

13) B. E. Warren: X-Ray Diffraction, Dover Publications, New York, (1990), 264.

14) G. K. Williamson and W. H. Hall: Acta Metall., 1 (1953), 22. https:// doi.org/10.1016/0001-6160(53)90006-6

15) T. Ungár and A. Borbély: Appl. Phys. Lett., 69 (1996), 3173. https:// doi.org/10.1063/1.117951

16) M. Kumagai, K. Akita, M. Imafuku and S. Ohya: Adv. Mater Res., 996 (2014), 39. https://doi.org/10.4028/www.scientific.net/ AMR.996.39

17) W. Gong, Y. Tomota, S. Harjo, Y. H. Su and K. Aizawa: Acta Mater. 85 (2015), 243. https://doi.org/10.1016/j.actamat.2014.11.029

18) T. Ungár, S. Harjo, T. Kawasaki, Y. Tomota, G. Ribárik and Z. Shi: Metall. Mater. Trans. A,48(2017), 159. https://doi.org/10.1007/s11661016-3845-4

19) S. Harjo, T. Kawasaki and S. Morooka: Adv. Exp. Mech., 2 (2017), 112. https://doi.org/10.11395/aem.2.0 112
20) M. Kumagai, M. E. Curd, H. Soyama, T. Ungár, G. Ribárik and P. J. Withers: Mater. Sci. Eng. A, 813 (2021), 141037. https://doi.org/ 10.1016/j.msea.2021.141037

21) Z. M. Shi, W. Gong, Y. Tomota, S. Harjo, J. Li, B. Chi and J. Pu: Mater. Charact., 107 (2015), 29. https://doi.org/10.1016/j.matchar. 2015.06.040

22) Y. Wang, Y. Tomota, T. Ohmura, S. Morooka, W. Gong and S. Harjo: Acta Mater., 184 (2020), 30. https://doi.org/10.1016/ j.actamat.2019.11.051

23) M. Wilkens: Phys. Status Solidi A, 2 (1970), 359. https://doi.org/ 10.1002/pssa.19700020224

24) T. Ungár, J. Gubicza, G. Ribárik and A. Borbély: J. Appl. Crystallogr., 34 (2001), 298. https://doi.org/10.1107/S0021889801003715

25) M. Moshtaghi and S. Sato: ISIJ Int., 59 (2019), 1591. https:// doi.org/10.2355/isijinternational.isijint-2019-077

26) M. Kumagai, K. Akita, M. Kuroda and S. Harjo: Mater. Sci. Eng. A, 820 (2021), 141582. https://doi.org/10.1016/j.msea.2021.141582

27) Y. Onuki, A. Hoshikawa, S. Sato, P. Xu, T. Ishigaki, Y. Saito, H. Todoroki and M. Hayashi: J. Appl. Crystallogr., 49 (2016), 1579. https://doi.org/10.1107/S160057671601164X

28) G. Ribárik: Ph.D. thesis, Eötvös Loránd University, (2008).

29) G. Ribárik, B. Jóni and T. Ungár: J. Mater. Sci. Technol., 35 (2019), 1508. https://doi.org/10.1016/j.jmst.2019.01.014

$30)$ J. I. Langford, D. Louër and P. Scardi: J. Appl. Crystallogr., 33 (2000), 964. https://doi.org/10.1107/S002188980000460X

31) G. Ribárik, T. Ungár and J. Gubicza: J. Appl. Crystallogr., 34 (2001), 669. https://doi.org/10.1107/S0021889801011451

32) W. B. Pearson: A Handbook of Lattice Spacings and Structures of Metals and Alloys, Vol. 2, Pergamon Press, Oxford, UK, (1967), 82.

33) A. Borbély, J. Dragomir-Cernatescu, G. Ribárik and T. Ungár: J. Appl. Crystallogr., 36 (2003), 160. https://doi.org/10.1107/ S0021889802021581

34) A. E. Lord, Jr. and D. N. Beshers: J. Appl. Phys., 36 (1965), 1620. https://doi.org/10.1063/1.1703098

35) J. E. Bailey and P. B. Hirsch: Philos. Mag., 5 (1960), 485. https:// doi.org/10.1080/14786436008238300

36) M. Kumagai, M. Imafuku and S. Ohya: ISIJ Int., 54 (2014), 206. https://doi.org/10.2355/isijinternational.54.206

37) M. Kumagai, M. Kuroda, K. Akita, M. Kamaya and S. Ohya: Mater. Sci. Forum, 941 (2018), 376. https://doi.org/10.4028/www.scientific. net/MSF.941.376

38) L. Lutterotti, S. Matthies, H.-R. Wenk, A. S. Schultz and J. W. Richardson, Jr.: J. Appl. Phys., 81 (1997), 594. https://doi.org/ $10.1063 / 1.364220$ 